This is a self-archived version of an original article. This version may differ from the original in pagination and typographic details.

Author(s): Valtanen, Kari

Title: The Psychiatrist's Role in Implementing Open Dialogue Model of Care

Year: 2019

Version: Accepted version (Final draft)

Copyright: @ 2019 Australian Association of Family Therapy

Rights: In Copyright

Rights url: http://rightsstatements.org/page//nC/1.0/?language=en

Please cite the original version:

Valtanen, K. (2019). The Psychiatrist's Role in Implementing Open Dialogue Model of Care. Australian and New Zealand Journal of Family Therapy, 40(3), 319-329.

https://doi.org/10.1002/anzf.1382 
A proposal for an article:

\section{THE PSYCHIATRIST'S ROLE IN IMPLEMENTING OPEN DIALOGUE MODEL OF CARE}

Kari Valtanen

Child and Adolescent Psychiatric Services, Western Lapland Hospital District, Finland

Contact : Kari Valtanen, kvaltane@ pp.inet.fi

Acknowledgements

I would like to thank Birgitta Alakare, Kristof Mikes-Liu and Campbell Thorpe for their helpful comments on earlier drafts of the article. 


\title{
THE PSYCHIATRIST'S ROLE IN IMPLEMENTING OPEN DIALOGUE MODEL OF CARE
}

\begin{abstract}
:
Open Dialogue approach is a family-oriented early intervention model for mental health problems developed in the health district of Western Lapland, Finland. Since the 1990s the psychiatric service system in Western Lapland Health Care District has been organised according to Open Dialogue principles and practice is applied to the treatment of any mental health concerns.

Open Dialogue approach is considering the patient and their family as active participants in the planning and implementation, rather than as objects, of treatment. The basic orientation of the treatment is psychotherapeutic. In daily work, the responsibility for the treatment process is shared with the case-specific team. The model of care requires a dialogical orientation from all staff members, psychiatrists included, to interact with the team and the client's network.

In this article I describe my observations of the role of the psychiatrist in implementing Open Dialogue model of care in psychiatric services leaning on my experiences of clinical work in the adolescent psychiatric team in Western Lapland.
\end{abstract}

\section{Learning points:}

1. Establishing shared understanding of the Open Dialogue practice and trust among all team members are crucial factors in order to respond dialogically to severe mental health crises of individuals and their close networks.

2. The psychiatrist is one member of the multiprofessional Need-adapted Open Dialogue team.

3. The model of care requires a new, dialogical orientation also from the psychiatrist.

4. The dialogical orientation and skills and shared trust in a team, are possible to require by a joint dialogical, family and network oriented therapeutic training process and continuous team supervision.

Key words: Open Dialogue, psychiatrist's role, psychiatric services, team work, family therapy 
"... there is mounting evidence that good practice in psychiatry primarily involves engagement with the non-technical dimensions of our work such as relationships, meanings and values."

Bracken et al 2012

In this paper, I describe my own understandings of the role of the psychiatrist in an Open Dialogue team based on my work in the adolescent psychiatric outpatient unit at Western Lapland Health care district and reflect on broader issues relating to psychiatry and therapeutic work with families and their networks.

Western Lapland is situated at the bottom of the Gulf of Bothnia in Northern Finland. The geographical area includes six municipalities, two of which are towns, Kemi and Tornio. There are about 65,000 inhabitants in Western Lapland. There is a 20-bed psychiatric hospital at Keropudas in Tornio, and six psychiatric outpatient teams; one at Keropudas hospital, one both in Tornio and Kemi, a general hospital psychiatric team and both child and adolescent psychiatric teams. About one third of all psychiatric staff (appr. 150 people) are stationed in the hospital and half in outpatient care, but many of the hospital staff do outpatient work, as well. In the smaller municipalities of the region there are also local mental health teams who collaborate in teamwork around the patients and their families.

Since early-1980s a new kind of psychiatric system was developed, now known as the Open Dialogue system of care. Development of this approach was based on the view of considering the patient and their family as

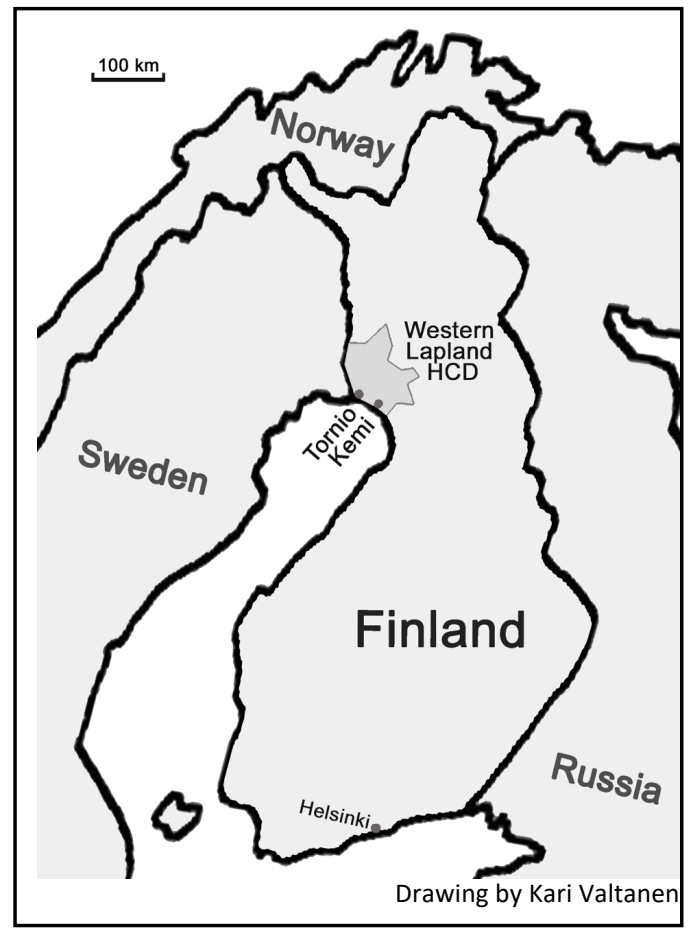
active participants in the planning and implementation, rather than as objects, of treatment (Seikkula et al 1995). A modification of a family oriented approach for the treatment of psychosis, the Need-Adapted Approach developed by Alanen and his team (Alanen et al 1991), was applied and further developed in Western Lapland. The concrete goals were to develop a comprehensive family- and network-centred psychiatric treatment model on the boundary between out-patient and in-patient care systems. In order to support the development of a research program and continuous therapeutic training programs for the staff were established. The training consists of a oneyear introductory program and a specific three-year program in family therapy. In addition, staff members have been are encouraged to undergo other forms of psychotherapy training, such as individual psychodynamic or cognitive psychotherapy. (Aaltonen, Seikkula \& Lehtinen 2011).

Since the 1990s the whole psychiatric service system in Western Lapland Health Care District has been organised according to Open Dialogue principles and practice is applied to the treatment of any mental health concerns, not only to psychotic crises. The aim of the work is to respond promptly to crises, while trusting on and supporting the resources of the family and other close network members. From the outset of treatment, attention is paid to carefully listen to the concerns and hopes of the people involved in the treatment, and so to enable dialogical interaction. When in dialogue, new words, understandings and opportunities are possible to emerge in crisis situations. In daily work, the responsibility for the treatment process is shared with the case-specific team. It includes 2-3 people from different professions and a psychiatrist. The model of care 
requires a new, dialogical orientation from all staff members, psychiatrists included, to interact with the team and the client's network.

I have worked part-time as a psychiatrist in the adolescent psychiatric team since 2003. I gained a fuller understanding of the Open Dialogue approach while completing my advanced level family therapy training in Western Lapland 2002 - 2004. The adolescent psychiatric unit serves young persons aged $13-23$ years of age. There are about 7,150 young persons within this age bracket in the region (Statistics Finland). There are no designated adolescent hospital beds in the district, and services are delivered as outpatient care. As we work closely with child welfare services, sometimes a young person is placed into a child protection unit, mainly due to the adolescent's behaviour problems or to lack of parental resources. Infrequently young people may be referred to the university hospital, which is located around $100 \mathrm{~km}$ south of Western Lapland, usually by health care centre GPs on call.

\section{The Open Dialogue approach in psychiatry}

The importance of responding quickly to all crisis situations is emphasized. Clients and network members can directly contact specialist services as the threshold for service access is kept low. The model of care emphasises the importance of families and network resources in understanding and managing psychological crises and other life stresses. Rapid response is important in mobilising the resources of the network. Timely engagement of the network utilises more possibilities to manage the crisis together and to prevent a decline in personal agency or problems becoming chronic.

The basic orientation of the treatment is psychotherapeutic. Psychiatric symptoms are viewed as people's responses to various forms of stress - traumatic experiences, current or past distress in life or relational conflicts - not as expressions of illness processes. We find the conversations that try to understand the context in which these "symptoms" emerge more useful than conversations that focus on diagnosing the problem. Thus, people's own understandings and agency are emphasized, and the conversations around psychiatric understandings, assessment, hospital admissions, medications etc. are not in focus.

The basic event of the treatment is a treatment meeting, in which the case-specific team invites, with client's consent, both client and her/his close network members (e.g. family members, school nurse, municipal social worker), that are engaged with the problem situation. According to Alanen (1997), the treatment meeting has three functions: to gather information about the problem; to build a treatment plan and make all decisions necessary based on the problem that was described in the conversation and to generate a psychotherapeutic dialogue. In Jaakko Seikkula's words "the focus is in constructing a joint dialogue between the participants ... to generate a new understanding of the circumstances related to the actual crisis" (Seikkula 2003). All available therapeutic modalities, including medication, are also discussed in treatment meetings and treatment plans are created together in open discussion.

The model of care has been developed over 35 years according to research, continuous feedback and accumulated experience. Collaboration with families and other network members in the region has been crucial for the development of the model. Research that has been focusing particularly on the treatment of acute psychosis is currently undergoing a 20-year follow-up study (Bergström et al 2017, 2018). Over the entire follow-up, the figures for durations of hospital treatment, disability allowances, and the need for neuroleptics remained significantly lower with Open Dialogue group. Findings indicated that many positive outcomes of Open Dialogue are sustained over a long time period. 


\section{Teamwork is central to the Open Dialogue approach}

After the first contact with psychiatric services, a case-specific team is formed around the client and her/his network that is responsible for the entire treatment process. Work is based on the need adapted care (e.g. Alanen 2009) that is tailored to the individual, changing needs of the clients and their close social network members in collaboration with wider network (like school, occupational health care, social services etc.).

Supporting the individual and the family's agency from the beginning of the work is prioritised above the professional assessment of the situation or the diagnosis of the individual. Too quick conclusions or interpretations on patient's situation or decisions taken by professionals may lead to a reduction in the patient, family and network involvement.

Work in teams does not emphasize the differences between professional backgrounds as the common goal is to promote dialogue and build shared understandings. The focus of the expertise of the team has shifted to facilitate collaborative, dialogical processes (e.g. Anderson1997, Laitila 2009). Common challenge for all is to listen to everyone's different voices and respond to them and to learn about the unique contexts of client's utterances. The practice of a dialogical team essentially requires equal participation of each member of the team in handling the complexity of crises and taking care of listening to every voice (e.g. Haarakangas et al 2007). All professionals have their own professional or personal voices as well, but they equal to any other voices in the polyphony of the situation. Working in a team enables listening to all members of the family and network as team members pay attention to different utterances.

The role of a psychiatrist is to be one member in a case-specific, dialogical team. According to the Finnish Health Care act (Ministry of Social Affairs and Health 2010), a physician oversees initiation and termination of special medical care and, for example, the patient's transfer to the hospital. These tasks may also be delegated to a case-specific team by a physician. In serious crisis situations, the psychiatrist is required to evaluate the patient's safety and the need for the possible involuntary treatment. It is often possible to conduct this evaluation in collaboration and the decision is made in a dialogical process rather than in isolation. While the decision lies with the psychiatrist in the end, they respect the perspective and input of the others.

Family therapeutic perspectives and ways of working have contributed greatly to the development of the working model. In order to implement a dialogical, family and network-oriented treatment model, the organisation has emphasised the importance of dialogical family therapy training for all the staff members. Joint education across professional disciplines has made it possible to have a shared understanding of, for example, the objectives of the work, dialogical practices and mutual collaboration. The insecurity and discomfort of difficult crisis situations calm down when a team is able to work together supporting each other, relying on listening to all involved and to provide for the necessary care of the process.

The role of the psychiatrist in the implementation of the Open Dialogue approach and principles

The Open Dialogue approach is guided by seven key principles that have emerged from the research programs and psychotherapy training: immediate care; family and network orientation; responsibility; flexibility and mobility; psychological continuity; tolerance of uncertainty; and dialogue (Seikkula, Alakare \& Aaltonen 2001). One way of scrutinizing the role of a psychiatrist in an Open Dialogue model of care is to look at their part in the implementation of the approach and its principles. In the following paragraphs I describe each principle and reflect my observations of the role of the psychiatrist in each according mainly to my lived experience at practice. 
Immediate help. There is no need for a referral for access to treatment, but the person themselves or any member of the network can contact the services. The initial contact is usually by telephone to a nurse on call, who is responsible to arrange first treatment meeting. The need of commencing a treatment process is decided in a joint conversation in the first treatment meeting. The psychiatrist is not often in the front line to meet a client and network, but rather gets involved when needed or in severe crises. Medical assessment or diagnosis are not seen as the primary focuses in the meeting but listening to various concerns and perspectives, and responding to them. The psychiatrist relies on team members ability to consult psychiatrist readily when they see an immediate need e.g. for examinations, medication, hospital care, etc. Were the psychiatrist to meet every client first, due to the small number of psychiatrists, the first meetings would be congested and access to the services would become more difficult.

Family and network orientation. Family and other close social network members are considered a key resource for understanding and supporting individuals in crises. The local network is actively taken into account and invited to collaborate when needed. Crises often affect family and other relations, so the working group may need to consider the support needs of all members of the network. Sometimes working with the network starts at the level of the imagination, for example, by pondering what concerns or thoughts would the non-present members of the family would have in the situation. Working with families and networks requires different kinds of orientation and skills in compared to the individual doctor-patient relationships that are emphasized in traditional psychiatric specialist training. Psychiatrists in our services have additional training in working with families and networks, as well, as this allows them to draw on the network's resources, collaborate with the network and contribute to meaningful dialogical conversations.

Responsibility. The responsible team takes care of the entire process of the need adapted care. The shared responsibility means, that all team members bring into consideration various important issues during the process, e.g. safety around different treatment decisions, concerns around suicidality, safety during the sessions for all people to express their own, even opposing voices etc, and that all issues raised are responded to. In crises, issues often emerge that require a quick response from the team. Responsive and flexible care is possible when the team has the support of the psychiatrist and other staff members. Psychiatrist's availability for brief team consultation when necessary by phone or visit is important in supporting the team and creating sense of safety to all. The trust needed between the team members and psychiatrist, as well, is developed by working together and in joint family therapeutic training and deepened in team supervisions and weekly team meetings where issues regarding the collaboration are openly discussed.

Flexibility. Each patient and family needs the most appropriate, need-adapted approach to their treatment. At the beginning of the treatment, appointments may be daily. The next meeting's place and time, and the participants to be invited, are agreed upon at each appointment. This need adapted approach requires flexibility from the team. On many occasions several team members must reschedule their timetables in order to enable the intensive, maybe daily work in crisis situation. The psychiatrist also participates in home visits and strives to be flexible for consultation with the team. Often in difficult crisis situations, the psychiatrist has to prioritize their work, as well. Often, however, an experienced team can, together with the local network, find the necessary solutions in crisis situations and, for example, agree on short hospital treatment or one-off sleeping pill or anxiolytic medication with the consent of the team's psychiatrist.

Continuity. The therapeutic relationship and shared understanding created between the network and the team are significant key factors in the treatment process. Particular attention has been paid to the maintenance of psychological continuity in treatment. The formed relationships should not be discontinued and, for example, replacement of the team members should be 
avoided and openly discussed. Treatment processes might last several years, so staff members should engage with the treatment as long as required

The responsible team creates the therapeutic relationship to the patient and relevant network members, and takes care of the process of care and foster the psychological continuity. Usually the psychiatrist cannot find time to work so closely part of the treatment process. Therefore the responsible psychiatrist should be considerate not to disrupt this working relationship between team members and the family, and to ensure continuity of the treatment across inpatient and community settings. If the patient needs temporary hospitalization, the outpatient team care should remain in charge of treatment, although the team is temporarily supplemented by a hospital team.

Tolerance of uncertainty. Crisis situations easily arouse anxiety among the team members, as well as family members. This can lead team members to hastily provide solutions to resolve a difficult situation, such as isolating the person from their family or immediately commencing a continuous medication. Psychiatrists often feel obliged to take crisis management "on their own shoulders". There is a risk of paralysing the client or network's own agency and ignoring their own knowledge and skills to alleviate the situation.

We consider the family and other close network relations as potential key resources of understanding and support for individuals in everyday life (e.g. McPherson et al 2014). In order to restore the agency of the individual and network, it is important for a psychiatrist, along with the other team members, not to rush to treatment solutions or understanding others too promptly. Often involuntary treatment or sudden commencing of medication may be confusing or even traumatic for the individuals. Listening carefully to the network members and thinking about different views can lead to solutions that support the network members' own abilities to act in crisis situations. When considering long-term medication, it would be good to consider having the conversation several times in order to consider and weight together different issues around medication: overall necessity, alternatives, possible effects and side-effects, fears and other possible meanings adhered to it, like influence of medication on identity, self-agency, relations, and so on.

Dialogism. The main goal of the treatment is to create a dialogue between the participants and their different internal voices (Seikkula J., Alakare B. \& Aaltonen J. 2001, Seikkula 2008). Team members should have the skills to foster dialogical conversations. In dialogical meeting a shared interactional space is created where the possibility of change is evolving through the exchange of utterances and responses. It is important for team members to listen carefully to the different words and expressions in a network meeting and respond to these, expression of emotions is also encouraged. The use of words should be adjusted to the ones used by network members and medical or psychological terms should be avoided. The psychiatrist contributes to listening to all the perspectives and participates in a multifaceted discussion of the themes the network members attach importance to. In discussions and reflections, the psychiatrist and the case-specific team can also provide their own understanding. The psychiatrist's personal and professional views are voices and perspectives among other voices and perspectives. The psychiatrist may be curious about controversial points of view, as well as bring out the background ideas to their opinions transparently.

\section{Reflections}

Collaboration is an important value and the starting point for my own job as a psychiatrist. I can only grasp the world from my own experiences, and I can never fully understand another person. It is important for me to listen to people reflect from their own experiences and to build a shared understanding in our mutual sharing. 
As a medical professional, I am aware of my position of power (e.g. UN Human Rights Council - June 2017) and how significantly my assessment might influence my clients. Substantial power is in use when people's experiences of life are interpreted and defined by professionals. It is essential that my own (benevolent) interpretations do not undervalue people's own experience, their own agency or resources. When an expert takes on the task of defining individual's life concerns, the agency moves away from the person concerned and they are objectified. It is, however, possible e.g. to reflect together with team members and contribute our understandings as "voices" to shared scrutiny with network involved.

In the medical approach, the role of a physician is central. The physician often takes charge of assessing the symptoms, formulating an initial diagnosis and planning the examinations and treatments. This approach might fit quite well with the treatment of somatic illness; however with problems of life experiences and lack of agency this approach does not promote the restoration of patient's functioning and sense of self-agency. Empirically psychiatric illnesses are difficult to demonstrate, there are no biological tests such as blood tests or brain scans that can be used to provide independent objective data in support of any psychiatric diagnosis, apart from dementia and some chromosomal disorders (Council for Evidence-based Psychiatry 2014). According to Thomas Insel, former director of National Institute of Mental Health, US: "DSM diagnoses are based on a consensus about clusters of clinical symptoms, not any objective laboratory measure. In the rest of medicine, this would be equivalent to creating diagnostic systems based on the nature of chest pain or the quality of fever" (Insel 2013). Medication mechanisms are also non-specific, the same medications are attempted to use to alleviate many psychological symptoms. Relational therapeutic help and support for daily functioning are key elements in all psychiatric care for all conditions.

The starting point for dialogical therapeutic help is not to start categorizing the problems and symptoms presented by people into the diagnostic "pigeon holes" and to provide generalized therapies according to these categories, but to create a unique treatment process to meet the concerns and needs of each individual and close network members. The life experiences, social contexts, health issues and so on of each human being are unique, multi-dimensional and complex. It is important that people are listened to in their unique life situations and that clinicians do not try to understand too quickly. Understanding that gradually and continually develops then advances the need adapted treatment process tailored specifically to the needs of the client and their network rather than to the diagnosis.

In Finnish society, many rehabilitation benefits or psychotherapies are granted only by a medical certificate which has a significant emphasis on medical diagnosis. The active involvement of service users in considering the preferred diagnosis is important to make it truly useful and as close to the person's own description of their situation as possible. Diagnoses may be perceived as misinforming, stigmatizing or otherwise harmful (Callard et al 2013, Pitt $L$ et al 2009). A shared discussion about the diagnosis is important as diagnoses can cause a lot of confusion. Service users have described that the diagnosis may first seem like an anxiety-easing explanation, but later it might become problematic or limit one's social identity.

The range of need adapted therapies also includes medication. Acute and temporary medication can help to reduce excessive anxiety and/or extended sleep problems. In the event of a severe mental health crisis, the situation can be greatly eased by temporary sleeping pills or anxiolytics. In Western Lapland practice we prefer to dispense one or two days of medication to the patient during the visits instead of giving prescriptions. This ensures the effective therapeutic help and relational support, and the continuation of the medication can avoided. When considering long-term medication, it is necessary to spend time in discussing the potential benefits and 
disadvantages of medication and to consider the various concerns and meanings that are related to the medication. Medication should not deteriorate cognitive functions, result in an addiction, cause physical/social harm or otherwise reduce the individual's agency.

The psychiatrist has been given a pivotal role in psychiatric care, and the doctor's attitudes and actions may influence the work groups operation considerably. Replacement of the psychiatrist, and the different approaches of a new psychiatrist, may confuse the work of the team. Psychiatrists should be aware of their role as part of a team and avoid setting up a hierarchical, monological position that can silence the dialogical and polyphonic culture of the team. To work dialogically and share responsibility over treatment processes, a democratic culture at workplace is a prerequisite. The psychiatrist is in a pivotal role to establish and nurture this democratic atmosphere.

In a dialogical approach, the main objectives are to listen to the different concerns and perspectives of the clients and network members on issues that matter to them, and to respond to their expressions, hopes and needs. When concerns can be examined at from many perspectives, the need adapted care and the unique ways of working with the client and the network will begin to evolve. What is crucial in treatment is to keep the clients and family members and their sense of agency at the centre. The agency or the definitions of the professionals, including the psychiatrist, are not so essential.

\section{What does the Open Dialogue approach mean to me personally?}

Most important and invigorating for me in my work is to stay attached to my values and dreams. The central part of my work is to listen carefully to my clients, collaborate and create dialogue around the issues meaningful to them, not to assess or analyse people or their experiences in life. When trying to understand the predicaments of people's lives, I can also reflect on my personal life experiences, which makes my work more human encounter. When I can draw both from my professional and personal life experiences, my professional role is less limited.

Therapeutic activities are collaborative and the responsibility for seeking new understandings are shared both with clients and team members, thus I feel less burdened and alone in my work. The relationship with my team members is more open and straightforward. It is essential to be able to trust to your team and have a sense of safety, as working with difficult crises might often evoke anxiety or painful memories in all professionals as well.

I have developed through my work experiences and trainings new kind of curiosity about listening to different voices and finding new perspectives in often complex and confusing crisis situations. When we allocate enough time for polyphonic dialogues, the initially incoherent experiences people express begin to connect to their relations, life histories and contexts, and become more understandable as utterances rather than as symptoms of psychiatric illnesses.

Dialogical thinking has also enriched my personal, relational life. Understanding, that everyone interprets the world from their own perspectives, I feel less competition about "being right" and more curiosity about different views of others.

\section{References:}

Aaltonen J., Seikkula J. \& Lehtinen K. (2011). The Comprehensive Open-Dialogue Approach in Western Lapland: I. The incidence of non-affective psychosis and prodromal states. Psychosis: Psychological, Social and Integrative Approaches, 3:3, 179-191

Alanen, Y. (1997). Schizophrenia: Its Origins and Need-Adapted Treatment. London: Karnac. 
Alanen Y.O., Lehtinen K., Rakkolainen V., Aaltonen J. (1991). Need-adapted treatment of new schizophrenic patients: experiences and results of the Turku Project. Acta Psychiatrica Scandinavica 1991: 83: 363-372.

Alanen Y.O. (2009). Towards a more humanistic psychiatry: Development of need-adapted treatment of schizophrenia group psychoses. Psychosis Vol. 1, No. 2, August 2009, 156-166

Andersen, T. (1987). The Reflecting Team: Dialogue and Meta-Dialogue in Clinical Work. Family Process 26:415-428

Anderson, H. (1997). Conversation, language and possibilities: A postmodern approach to therapy. New York, NY: Basic Books.

Bergström, T., Alakare, B., Aaltonen, J., Mäki, P., Köngäs-Saviaro, P., Taskila, J. J., \& Seikkula, J. (2017). The long-term use of psychiatric services within the Open Dialogue treatment system after first-episode psychosis. Psychosis, 9(4), 310-321.

Bergström, T., Seikkula, J., Alakare, B., Mäki, P., Köngäs-Saviaro, P., Taskila, J. J., Aaltonen, J. (2018). The family-oriented Open Dialogue approach in the treatment of first-episode psychosis: Nineteen-year outcomes. Psychiatry Research, 270, 168-175.

Bracken, P., Thomas, P., Timimi, S., Asen, E., Behr, G., Beuster, C., Bhunnoo, S., Brown, I., Chhina, N., Double, D., Downer, S., Evans, C., Fernando, S., Garland, M. R., Hopkins, W., Huws, R., Johnson, B., Martindale, B., Middleton, H., Moldavsky, D., Moncrieff, J., Mullins, S., Nelki, J., Pizzo, M., Rodger, J., Smyth, M., Summerfield, D., Wallace, J., \& Yeomans, D. (2012). Psychiatry beyond the current paradigm. The British Journal of Psychiatry 2012, 201, 430-434.

Callard, F., Bracken, P., David, A., Sartorius, N. (2013) Has psychiatric diagnosis labelled rather than enabled patients? BMJ: British Medical Journal (Online); London Vol. 347, (Jul 25, 2013). DOI:10.1136/bmj.f4312

Council for Evidence-based Psychiatry (2014). No-known-biological-causes-010314.pdf. Http://cepuk.org/unrecognised-facts/no-biological-causes/

Haarakangas, K., Seikkula, J., Alakare, B., \& Aaltonen, J. (2007). Open Dialogue: An approach to psychotherapeutic treatment of psychosis in northern Finland. In Anderson H. \& Gehart D. (Eds.), Collaborative Therapy: Relationships and Conversations That Make a Difference. (pp. 221-233). New York, NY US: Routledge

Insel, T. (2013). Post by Former NIMH Director Thomas Insel: Transforming Diagnosis. https://www.nimh.nih.gov/about/directors/thomas-insel/blog/2013/transforming-diagnosis.shtml

Laitila, A. (2009). The expertise question revisited: Horizontal and vertical expertise. Contemporary Family Therapy, (31), 239-250.

McPherson K. E., Kerr S., McGee E., Morgan A., Cheater F. M., McLean J. and Egan J. (2014). The association between social capital and mental health and behavioural problems in children and adolescents: an integrative systematic review. BMC Psychology 2:7.

Ministry of Social Affairs and Health, Finland (2010). Health Care Act. https://www.finlex.fi/en/laki/kaannokset/2010/en20101326 20131293.pdf

Pitt L. et al (2009) Impact of a diagnosis of psychosis: user-led qualitative study. Psychiatric Bulletin (2009), 33, 419-423. doi: 10.1192/pb.bp.108.022863 
Seikkula, J. (2008). Inner and outer voices in the present moment of family and network therapy. Journal of Family Therapy, 30, 478-491.

Seikkula, J., Aaltonen, J., Alakare, B., Haarakangas, K., Keranen, J., \& Sutela, M. (1995). Treating psychosis by means of Open Dialogue. In S. Friedman (Ed.), The reflecting team in action (pp. 62-80). New York, NY: The Guilford Press.

Seikkula J., Alakare B. \& Aaltonen J. (2001). Open Dialogue in psychosis I: An introduction and case illustration. Journal of Constructivist Psychology, 14:4, 247-265

Seikkula J. (2003). Dialogue is the change: Understanding psychotherapy as a semiotic process of Bakhtin, Voloshinov, and Vygotsky. Human Systems: The Journal of Systemic Consultation \& Management. Volume No. 14, issue 2, 2003, pp. 83-94

Seikkula, J., Alakare, B., \& Aaltonen, J. (2001). Open Dialogue in psychosis I: An introduction and case illustration. Journal of Constructivist Psychology, 14 (4), 247-265.

Statistics Finland. 2019. Population structure. [ONLINE] Available at: http://pxnet2.stat.fi/PXWeb/pxweb/en/StatFin/StatFin_vrm_vaerak/statfin_vaerak_pxt_11re.px/. [Accessed 31 May 2019].

UN Human Rights Council - June 2017 - Report of the Special Rapporteur on the right of everyone to the enjoyment of the highest attainable standard of physical and mental health.

https://reliefweb.int/sites/reliefweb.int/files/resources/G1707604.pdf 